\title{
Follow-Up Study of Electronystagmographic Findings in Friedreich's Ataxia Patients and Evaluation of Their Relatives
}

\author{
L. Monday, J. Lespérance, B. Lemieux and H. Saint-Vincent
}

\begin{abstract}
Fourteen Friedreich patients (F group) who had undergone a first electronystagmogram (E.N.G.) reported in 1978, had the same test 12 to 24 months after the first one. In the second study, there are more patients with bilateral hypoactive caloric nystagmus failure of fixation suppression, ocular dysmetria, irregular pendulum tracking and ocular flutter. These signs are probably most representative of the progression of the disease. Nineteen unaffected relatives of these patients ( $\mathrm{H}$ group) also had an electronystagmogram but no special "familial" electronystagmographic pattern could be identified. Irregular ocular poursuit, nearly invariable in the $\mathrm{F}$ group but absent in the $\mathrm{H}$ group, was one of the most important differences between patients and their relatives.
\end{abstract}

RÉSUMÉ: Nous avons réévalué de 12 à 24 mois plus tard, 14 malades souffrant d'ataxie de Friedreich (groupe F) dont l'électronystagmogramme avait été rapporté en 1978. Dans la présente étude, on note plus d'absence de suppression fixative et plus de nystagmus calorique hypoactif bilatéral, plus de dysmétrie oculaire, de "tracking" pendulaire irrégulier et de "flutter" oculaire. Ces signes sont probablement représentatifs de la progression de la maladie. Nous avons fait l'électronystagmogramme chez 19 parents non atteints de ces patients (groupe $\mathrm{H}$ ), mais nous $n$ 'avons décelé aucun patron familial. Une des plus importantes différences entre les deux groupes réside dans la présence presque totale d'une poursuite oculaire irrégulière chez les patients (groupe F) et son absence complète chez les parents (groupe $\mathrm{H}$ ).

Can. J. Neurol. Sci. $1984 ; 11: 570-573$

In 1978, we reported a series of sixteen typical Friedreich patients who had had an electronystagmographic evaluation (E.N.G.) (Monday et al., 1978). Among many abnormalities, the most striking features were ocular dysmetria, irregular tracking of the pendulum, ocular flutter and failure of fixation suppression. Bilateral weakness of the caloric response was found in four patients and a unilateral weakness in one patient.

A second E.N.G. test was performed twelve to twenty-four months later in fourteen of the sixteen patients previously reported to evaluate progression of the oculomotor function. Nineteen unaffected relatives of the patients had the same electronystagmographic testing (E.N.G.) to determine if similar abnormalities of the oculomotor pattern were present.

\section{Material AND Methods}

Fourteen of the sixteen typical Friedreich's patients whose oculomotor function had been previously studied with electronystagmography (E.N.G.) had the same test between twelve and twenty-four months later. The equipment and the different parameters studied were the same. The electronystagmograph was a MINGOGRAPH 800 SIEMENS with 4 channels: 2 DC and $2 \mathrm{AC}$.

The patient was securely strapped on a comfortable, motorized position table (Royco) and silver chloride electrodes were applied around the eyes, as described in Barber's manual of electronystagmography (Barber et al., 1980), and the procedure was carried out in dim light. The head of the patient was first maintained at $30^{\circ}$ from the horizontal and calibrations performed in order. Eye deviations of 1 degree corresponded to a deflection of 1 millimiter on the graph. Position testing was then performed, the patient being placed in seven other positions and left in each of them for 1 minute. The eyes were closed and the patient mentally alert during all the positional testing except for a brief period at the beginning of the recording where the tracing was made with eyes closed without mental awareness and then with eyes opened. Next came the pendulum tracking test, followed by a search for gaze nystagmus, eyes opened and eyes closed, with an eye deviation of 20 degrees, horizontal right and left and vertical up and down. Caloric irrigations ended the procedure, first with hot $\left(44^{\circ} \mathrm{C}\right)$, then with cold $\left(30^{\circ} \mathrm{C}\right)$ water. New calibrations 
preceeded every test. In the present series, calibration periods were prolonged somewhat between 30 and 60 seconds so that a better evaluation of the oculomotor function could be made.

Nineteen unaffected relatives of the fourteen patients underwent the same test. They were father and/or mother (obligatory heterozygotes) and brother or sister (normal or possible heterozygotes) of the patients.

\section{FINDINGS}

1. Comparison between E.N.G. No. 1 and E.N.G. No. 2.

a) Positional nystagmus

As in the previous study, positional nystagmus was an uncommon finding.

b) Rebound nystagmus and periodic alternating nystagmus

None was found in either study

\section{c) Calorics}

There was no absence of response nor hyperactive response in either test. In the second E.N.G., there was still one unilateral weakness as in the first E.N.G. and also one premature caloric reversal as in the first test, but in a different patient. Bilateral weakness was found in five subjects $(36 \%)$ in the second test against four in the first one and failure of fixation suppression is found in six patients $(43 \%)$ as compared to two $(14 \%)$ in the previous observation.

\section{d) Ocular dysmetria}

Twelve patients (86\%) presented hypermetric saccades in the previous E.N.G. and fourteen (100\%) in the second E.N.G.; nine patients $(64 \%)$ presented hypometric saccades in the first E.N.G. and fourteen (100\%) in the second test.

\section{e) Pendulum tracking}

Abnormal pendulum tracking was a very common finding in the first test (twelve patients or $86 \%$ ) and was also one of the most constant features (thirteen patients or $93 \%$ ) in the second test.

\section{f) Ocular flutter}

Ocular flutter was observed in five subjects (36\%) of the first study and is now present in eight (57\%).

\section{Comparison between Friedreich patients and their relatives.}

Since there are fourteen Friedreich patients $(F)$ and nineteen unaffected relatives $(H)$, the differences between the two groups is expressed in percentage.

\section{a) Gaze nystagmus.}

There was unilateral horizontal gaze nystagmus with eyes closed in $42 \%$ of $\mathrm{H}$ against $14 \%$ of $\mathrm{F}$. Also, more vertical upward gaze nystagmus, eyes closed, was found in $\mathrm{H}: 21 \%$ against $0 \%$ in $\mathrm{F}$. Vertical downward nystagmus, eyes opened, was found in $0 \%$ of $\mathrm{H}$ and $7 \%$ of $\mathrm{F}$.

\section{b) Caloric response}

$10 \%$ of $\mathrm{H}$ and $7 \%$ of $\mathrm{F}$ show a unilateral weakness. There is a bilateral weakness in $36 \%$ of $\mathrm{F}$ and failure of fixation suppression in $43 \%$ of $\mathrm{F}$ while none of these abnormalities in $\mathrm{H}$.

\section{c) Ocular dysmetria}

Since it is not uncommon to observe some hypermetric saccades in the general population, here we consider only those who presented $51 \%$ or more overshooting and undershooting during the calibrations before each sequence of the E.N.G. $36 \% \mathrm{~F}$ presented horizontal hypermetric saccades and $29 \%$ vertical hypermetric saccades as compared with $0 \% \mathrm{H}$ for both abnormalities. Horizontal hypometric saccades are also found in $21 \%$ $\mathrm{F}$ against $5 \% \mathrm{H}$ and vertical hypometric saccades in $7 \% \mathrm{~F}$ against $5 \% \mathrm{H}$.

\section{d) Irregular pendulum tracking}

This abnormality is almost constant in F (93\%) but absent in H.

e) Ocular flutter

$57 \% \mathrm{~F}$ and $5 \% \mathrm{H}$ present some ocular flutter.

\section{Comments}

\section{A. Comparison between E.N.G. No. 1 and E.N.G. No. 2} (Table 1)

Table 1: Comparison of Findings Between the First and the Second Electronystagmograms of the 14 Friedreich Patients

\begin{tabular}{|c|c|c|}
\hline & ENG No. 1 & ENG No. 2 \\
\hline $\begin{array}{l}\text { CALORICS } \\
\text { Bilateral weakness } \\
\text { Failure of fixation suppression }\end{array}$ & $\begin{array}{l}4(29 \%) \\
2(14 \%)\end{array}$ & $\begin{array}{l}5(36 \%) \\
6(43 \%)\end{array}$ \\
\hline $\begin{array}{l}\text { OCULAR DYSMETRIA } \\
\text { Hypermetric saccades } \\
\text { Hypometric saccades }\end{array}$ & $\begin{array}{r}12(86 \%) \\
9(64 \%)\end{array}$ & $\begin{array}{l}14(100 \%) \\
14(100 \%)\end{array}$ \\
\hline ABNORMAL PENDULUM TRACING & $12(86 \%)$ & $13(93 \%)$ \\
\hline OCULAR FLUTTER & $5(36 \%)$ & $8(57 \%)$ \\
\hline
\end{tabular}

An interesting finding was the presence of a premature caloric reversal in E.N.G. No. 2, but not in the same subject as in E.N.G. No. 1: so, for this single finding, one patient "improves" while another "deteriorates". It is probable that this significiant abnormality is not constantly present.

Bilateral hyporeactive caloric nystagmus seems a more reliable sign of the evolution of the disease: one patient showed this new abnormal feature in his E.N.G. No. 2 and may be added to the other four in whom it was found in the first test. Also, a further four patients failed to suppress their post caloric nystagmus by fixation in the second E.N.G., for a total of six subjects as compared with two in the previous observation.

These caloric abnormalities have already been described by others (Baloh et al., 1975; Kirkham et al., 1979; Ell et al., 1984). Failure of fixation suppression is compatible with spino cerebellar degeneration (Coats, 1970); bilateral weakness of caloric responses in Friedreich's ataxia may be attributed to associated vestibular nerve atrophy (Baloh et al., 1979), or to brain stem involvement (Dionne et al., 1979).

Similarly, more patients had ocular dysmetria, irregular pendulum tracking and ocular flutter in the second test. These oculomotor defects may not be specific to Friedreich's ataxia, but they are found in a large number of Friedreich's patients after a 12 to 24 months evolution and may be interpreted as manifestations of the progression of the disease. 
Recently, a more consistent oculomotor pattern has been documented in a larger and comparable group of patients with Friedreich's ataxia (Furman et al., 1983). This pattern included fixation instability, inaccurate saccades with normal peak velocity, impaired smooth pursuit and optokinetic slow phases, decreased vestibulo-ocular reflex gain, and impaired visual-vestibular interaction.

\section{B. Comparison between Friedreich patients and their relatives} (normal or possible heterozygotes) (Table 2)

Table 2: Comparison of Findings Between Friedreich Patients And Their Heterozygotes

\section{GAZE NYSTAGMUS}

Unilateral horiz., eyes closed

Vertical upward, eyes closed

Vertical downward, eyes opened

\begin{tabular}{c} 
Non Friedreich \\
Relatives \\
(normal or \\
possible \\
heterozygote) \\
\hline
\end{tabular}

Friedreich

\section{CALORICS}

Unilateral weakness

Bilateral weakness

Failure of fixation suppression

$\begin{array}{rr}42 \% & 14 \% \\ 21 \% & 0 \% \\ 0 \% & 7 \% \\ & \\ & \\ 10 \% & 7 \% \\ 0 \% & 36 \% \\ 0 \% & 43 \%\end{array}$

\section{OCULAR DYSMETRIA}

Horizontal hypermetric saccades

Vertical hypermetric saccades

Horizontal hypometric saccades

Vertical hypometric saccades

\begin{tabular}{lcc} 
ABNORMAL PENDULUM TRACKING & $0 \%$ & $93 \%$ \\
OCULAR FLUTTER & $5 \%$ & $57 \%$ \\
\hline
\end{tabular}

Nineteen non Friedreich relatives $(\mathrm{H})$ from seven families, of our fourteen patients (F) were submitted to the same E.N.G. testing. There was more gaze nystagmus in $\mathrm{H}$ than in $\mathrm{F}$ as noted earlier, both in the horizontal and the vertical gaze, but all with eyes closed, which is a less significant finding.

Unilateral caloric weakness was found in a small number of subjects in both groups ( $1 \mathrm{~F}$ and $2 \mathrm{H}$ ). The weakness in the $\mathrm{F}$ patient is "border line". In the clinical evaluation of one of the $H$ subjects, there was no history of dizziness but a slight bilateral neuro-sensorial hearing loss while the other $\mathrm{H}$ subject mentions a vague dizziness attributed to tension. This same person also has a slight bilateral mixed hearing loss. On the other hand, bilateral weakness and failure of fixation suppression, found in $36 \%$ and $43 \%$ of patients respectively in our series, may be considered as more significant findings related to the progression of the disease: none of the relatives present these abnormal findings.

There is a clear distinction between groups $\mathrm{F}(36 \%)$ and $\mathrm{H}$ $(0 \%)$ for hypermetric saccades but the difference is less marked for hypometric saccades, especially in the vertical hypometric saccades (horizontal hypometric saccades: F $21 \%$ and $\mathrm{H} 5 \%$; vertical hypometric saccades: $\mathrm{F} 7 \%$ and $\mathrm{H} 5 \%$ ). A certain degree of overshooting and undershooting is present in the general population and this is the reason why we considered

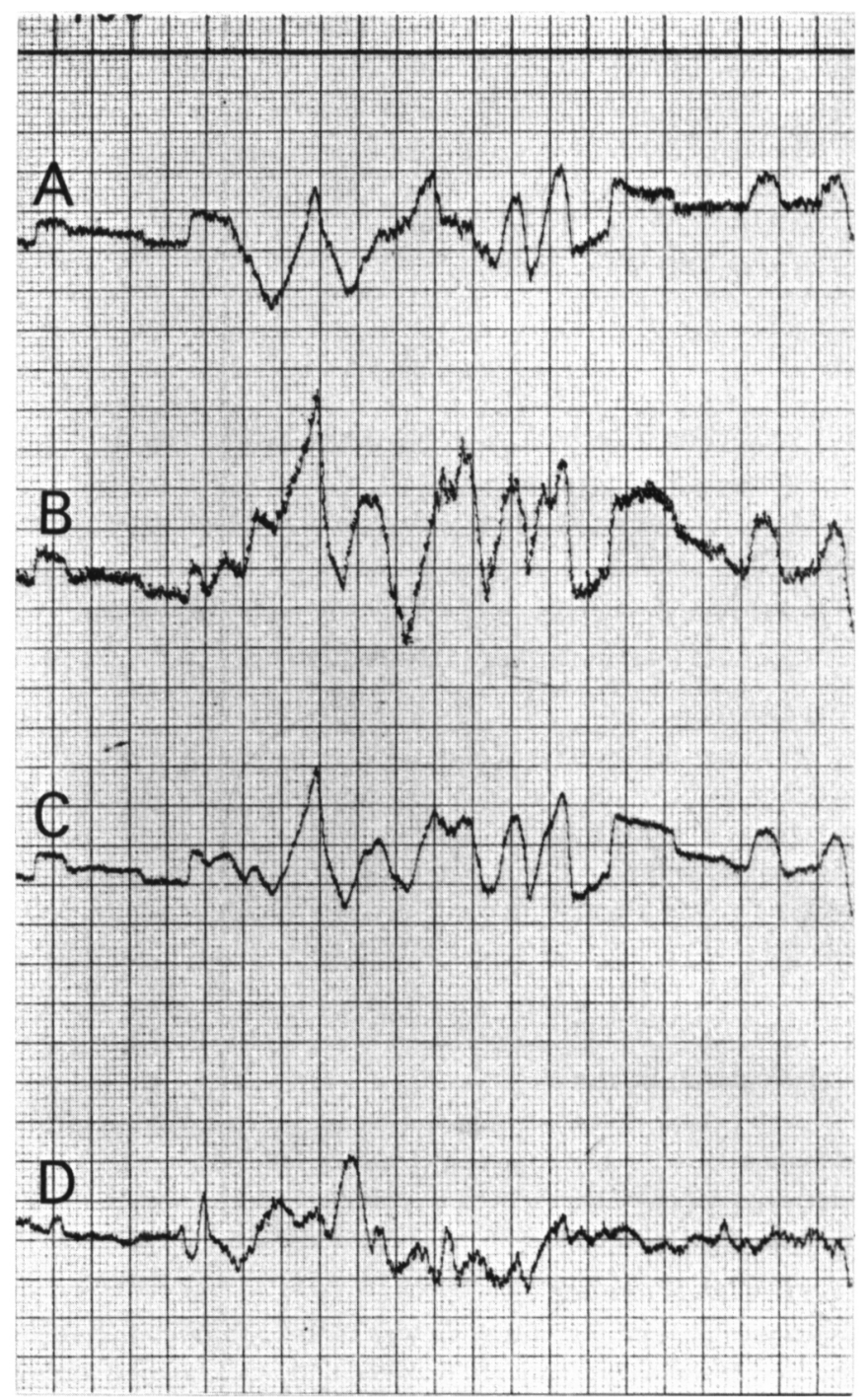

Figure I-Ocularflutter in a non-Friedreich relative. (A: right eye, D.C.:B left eye, D.C.; C: both eyes together, A.C.; D: vertical lead right eye, A.C.)

this feature only when it was present in $51 \%$ or more of the saccades. But, in fact, even considering its presence in $51 \%$ or more of the calibration saccades, the percentages are not very high.

Irregular pendulum tracking is certainly one of the most prominent central abnormalities and is very significant in the present study: $93 \% \mathrm{~F}$ against $0 \% \mathrm{H}$. This sign is one of the most reliable for central lesions.

Ocular flutter is an interesting feature: more patients had some in the second E.N.G. and it was found in one (5\%) of the non-Friedreich (Fig. 1) relatives belonging to a family with two Friedreich members who both present this abnormality. The number of subjects is too small to establish a significant statistical correlation for this finding but it would be interesting to look for "ocular flutter" in a large comparative series. This subject has no other abnormal finding in her E.N.G.

\section{CONClusion}

This follow-up study compares electronystagmographic findings in Friedreich patients 12 to 24 months after their first E.N.G. 
There are some significant differences for: bilateral hypoactive caloric nystagmus, failure or fixation suppression, ocular dysmetria, irregular pendulum tracking and ocular flutter. These signs are probably most representative of the progression of the disease.

The study of the relatives of Friedreich's patients does not define a special pattern of oculomotor disabilities which could be associated with the disease and so we failed to find "familial" electronystagmographic characteristics. There is no correlation in abnormal findings between Friedreich's patients and their relatives; this observation had also been previously reported in another study (Kirkham et al., 1979).

It should also be mentioned that we do not consider E.N.G. findings as diagnostic of Friedreich's disease, because of their variability and non-homogeneity (see also Ell et al., 1984). However E.N.G. testing is a useful marker of evolution of the disease.

\section{REFERENCES}

Baloh RW, Honrubia V (1979) Electronystagmography. In: (Baloh RW, ed), Clinical Neurophysiology of the Vestibular System, Philadelphia, FA Davis Co, ch 5.

Baloh RW, Konrad HK, Honrubia V (1975) Vestibulo-ocular function in patients with cerebellar atrophy. Neurology 25: 160-168.

Barber HO, Stockwell CW (1980) Manual of electronystagmography, 2nd ed, The CV Mosby Co, St-Louis.

Coats AC (1970) Central electronystagmographic abnormalities. Arch Otol 92: 43-53.

Dionne J, Wright G, Barber HO, Bouchard R, Bouchard JP (1970) Oculomotor and vestibular finding in autosomal recessive spastic ataxia of Charlevoix-Saguenay. Can J Neurol Sci 6: 177-184.

Ell J, Prasher D, Rudge P (1984) Neuro-otological abnormalities in Friedreich's ataxia. J Neurol Neurosurg \& Psychiat 47: 26-32.

Furman JM, Perlman S, Baloh RW (1983) Eye movements in Friedreich's ataxia. Arch Neurol 40: 400-410.

Kirkham TH, Guitton D, Katsarkas A, Kline LB, Andermann E (1979) Oculomotor abnormalities in Friedreich's ataxia. Can J Neurol Sci 6: 167:172.

Monday LA, Lemieux B, Saint-Vincent H (1978) Clinical and electronystagmographic findings in Friedreich's ataxia. Can J Neurol Sci 5: $71-73$. 